\title{
Requirement of dopamine signaling in the amygdala and striatum for learning and maintenance of a conditioned avoidance response
}

\author{
Martin Darvas, ${ }^{1}$ Jonathan P. Fadok, ${ }^{2}$ and Richard D. Palmiter ${ }^{1,3,4}$ \\ ${ }^{1}$ Department of Biochemistry, University of Washington, Seattle Washington 98195, USA; ${ }^{2}$ Graduate Program in Neurobiology, \\ University of Washington, Seattle Washington 98195, USA; ${ }^{3}$ Howard Hughes Medical Institute, University of Washington, \\ Seattle Washington 98195, USA
}

\begin{abstract}
Two-way active avoidance (2WAA) involves learning Pavlovian (association of a sound cue with a foot shock) and instrumental (shock avoidance) contingencies. To identify regions where dopamine (DA) is involved in mediating 2 WAA, we restored DA signaling in specific brain areas of dopamine-deficient (DD) mice by local reactivation of conditionally inactivated Th genes using viral gene therapy. Among all targeted areas-prefrontal cortex (PFC), amygdala, ventral striatum, dorsal striatum, and whole striatum-only restoration of DA signaling to both the whole striatum together with the amygdala enabled DD mice to acquire 2WAA. However, after prolonged overtraining during which DD mice had DA synthesis systemically reconstituted pharmacologically with L-3,4-dihydroxyphenylalanine (L-Dopa), DA signaling in the striatum alone was sufficient to maintain 2WAA, whereas DA signaling in the PFC together with the amygdala was insufficient to maintain 2WAA. Our results indicate that learning 2 WAA requires DA signaling in both the amygdala and the entire striatum; however, after sufficient training, DA signaling in the striatum alone can maintain the learned avoidance behavior.
\end{abstract}

[Supplemental material is available for this article.]

\section{Introduction}

Besides its involvement in drug-seeking, motor control, reward-learning, motivation, and attentional processes (Dayan and Balleine 2002; Schultz 2002; Dalley et al. 2004; Wise 2004), the dopamine (DA) system has also been associated with fearrelated learning (Lamont and Kokkinidis 1998; Greba et al. 2001; Pezze and Feldon 2004; de Oliveira et al. 2009; Fadok et al. 2009). DA neurons that are important for these behaviors reside predominantly in the substantia nigra pars compacta (SNc), which projects mainly to the dorsal striatum (caudate putamen, $\mathrm{CPu}$ ), and the ventral tegmental area (VTA), which projects to the ventral striatum (nucleus accumbens, NAc), medial part of the $\mathrm{CPu}$, and to cortical and limbic areas (Bjorklund and Dunnett 2007). These midbrain DA cells respond to aversive events by changing their electrophysiological activity (Joshua et al. 2008; Brischoux et al. 2009). Among the limbic DA projection areas, the amygdala is known to be critically important for fear-related behaviors (Seymour and Dolan 2008; Ehrlich et al. 2009; Shionoya and Datiche 2009) and DA levels in the amygdala increase during aversive events (Kalivas and Duffy 1995).

The two-way active avoidance (2WAA) paradigm differs from some commonly used fear-associated learning paradigms in that it requires not only associating a cue with a foot shock, but also learning a foot-shock avoidance strategy. This conditioned avoidance is strongly disrupted by antipsychotic drugs, many of which mediate their effects by blockade of DA receptors (Davidson and Weidley 1976; van der Heyden and Bradford 1988; Smith et al. 2007). A role for the striatum in avoidance behavior has been long established (Posluns 1962; Fibiger et al. 1974) and, more

\footnotetext{
${ }^{4}$ Corresponding author.
}

E-mail palmiter@u.washington.edu; fax (206) 543-0858.

Article is online at http://www.learnmem.org/cgi/doi/10.1101//m.2041211. importantly, ablation of DA neurons with neurotoxins also implicates DA signaling to the striatum in conditioned avoidance (Koob et al. 1984; Da Cunha et al. 2002).

Our lab has generated a mouse model of DA deficiency, the flox-stop dopamine-deficient (DD) mouse, which has conditionally inactive $T h$ genes that can be reactivated by action of Cre recombinase (Hnasko et al. 2006). The inability of these DD mice to synthesize DA can be bypassed by administration of L-3,4-dihydroxyphenylalanine (L-Dopa), which can be converted into DA. This allows investigating behavior in either presence or complete absence of DA (Palmiter 2008). In addition to this systemic pharmacological restoration, DA synthesis can be restored in DD mice by injecting brain regions of interest with a Cre recombinase-expressing virus (CAV2-Cre) that is taken up by terminals of cells projecting to the injection area and retrogradely transported back to the cell body. Thus, we can permanently restore DA synthesis in DD mice in a highly region-specific manner and then examine the role of DA in those areas for 2WAA (Darvas and Palmiter 2009, 2010). Because norepinephrine signaling is selectively restored and normal in DD mice (Hnasko et al. 2006), all behaviors observed in this model are attributable to DA and not norepinephrine, which is important since norepinephrine influences the strength of fear memories (McGaugh 2004).

\section{Results}

Restoration of DA signaling to DD mice

To identify brain regions where DA is necessary for 2WAA, we reactivated the Th gene in DD mice by bilaterally injecting CAV2-Cre into the prefrontal cortex (PFC) plus amygdala, striatum, striatum plus PFC, striatum plus amygdala, NAc plus amygdala, and $\mathrm{CPu}$ plus amygdala. Injections targeting the whole striatum were done by dual injections into the $\mathrm{CPu}$ along with the NAc. We 
A
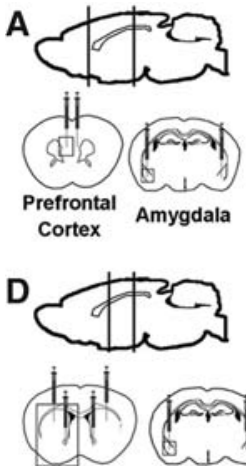

Striatum

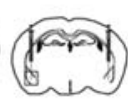

Amygdala
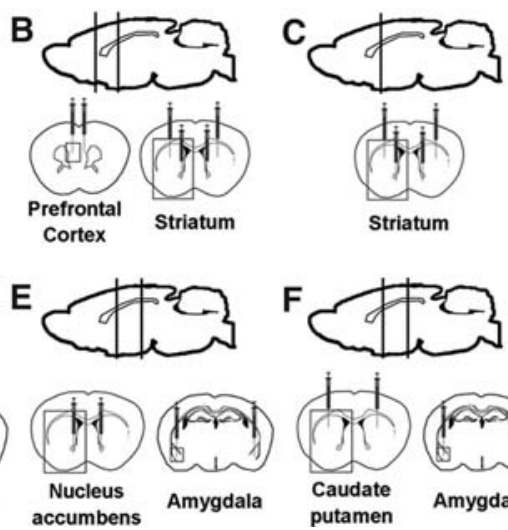
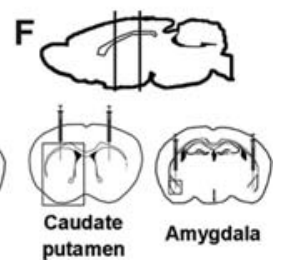

Figure 1. Schematic illustrations of targeted areas and needle placement for CAV2-Cre injections: PFC plus amygdala $(A)$, PFC plus whole striatum $(B)$, whole striatum $(C)$, whole striatum plus amygdala $(D)$, NAc plus amygdala $(E)$, and CPu plus amygdala $(F)$. Each syringe represents a viral injection and the syringe tips specify the injection depth. Regions of interest that are shown in Figure 2 are marked by boxes.

designated these mice as virally rescued or vrDD mice. Wild-type littermates (sham controls) were also injected with CAV2-Cre at the same coordinates. Figure 1 shows schematically the needle placements for these injections together with black boxes denoting areas containing the PFC, striatum, and amygdala (Fig. 1A-F).

Because we did not find any differences in TH immunostaining or behavior between the various groups of sham controls they were grouped together for presentation of our results. Whereas TH immunostaining was absent in DD mice that were not injected into the striatum, targeting NAc plus $\mathrm{CPu}$ with CAV2-Cre restored TH immunostaining to the whole striatum of vrDD mice (Fig. 2AD). Likewise, TH staining in the amygdala (Fig. 2E-H) and PFC (Fig. 2I-L) increased greatly over that contributed by noradrenergic fibers in vrDD mice that were injected in those areas. Targeting viral injection to either NAc or CPu resulted in restoration of TH staining in each respective area (Fig. 2M-O). Although injection of CAV2-Cre into the $\mathrm{CPu}$ alone restored $\mathrm{TH}$ staining in both the dorsolateral and dorsomedial striatum, the staining observed in the dorsolateral striatum was more intense than in the dorsomedial striatum. Because some of the injections into the $\mathrm{CPu}$ also resulted in weak restoration of TH staining in the NAc (not shown), we included only those vrDD-CPu mice into our behavioral analysis that had no TH staining in the NAc. The histology shown here is from this subset of vrDD mice that had TH staining exclusively restored to the dorsal striatum. Injection of CAV2-Cre into the NAc also resulted in weak restoration of TH staining in the dorsomedial striatum; hence, vrDD mice that received viral injections into both the CPu and NAc show a stronger TH staining in the dorsomedial striatum than mice that received viral injections into the $\mathrm{CPu}$ alone.

Taken together, the TH immunostaining patterns confirm that we generated mice DA synthesis restricted to PFC plus amygdala (Fig. 2B,F,J), striatum plus PFC (Fig. 2C,G,K), striatum (Fig. 2D,H,L), striatum plus amygdala (Fig. 2M,P), NAc plus amygdala (Fig. 2N,Q), and $\mathrm{CPu}$ plus amygdala (Fig. 2O,R). Supplemental Table 1 shows the number of sham-control and vrDD mice that were generated and how they were assigned to the experimental conditions.

\section{Learning 2 WAA requires DA signaling in the striatum and amygdala}

All mice were trained with 20 trials per block, 5 blocks per day for $2 \mathrm{~d}$. Two measurements were taken to analyze learning of

2WAA: latencies to respond to the sound cue (escape latency) and the percentage of avoidance responses. First, we tested if restriction of DA synthesis to the amygdala and PFC (PFC and Amy) alone would be sufficient to allow for 2WAA. To overcome the inactivity of mice without striatal DA, we used caffeine (15 mg/kg i.p.) to stimulate both the vrDD and the sham-control mice. Whereas both saline- and caffeine-treated sham-control mice performed 2WAA to a similar degree, caffeine-stimulated vrDD-PFC and Amy mice did not show 2WAA (Fig. 3A-C). Locomotor activity was similar between groups as indicated by repeated-measures (RM) two-way ANOVA of intertrial shuttles, which showed significant effects for training $\left(F_{(9,189)}=6.75, P<\right.$ $0.01)$ and training-group interaction $\left(F_{(18,189)}=2.73, P<0.01\right)$, but not for group $\left(F_{(2,189)}=1.70, P>0.05\right)$. Post-hoc comparisons

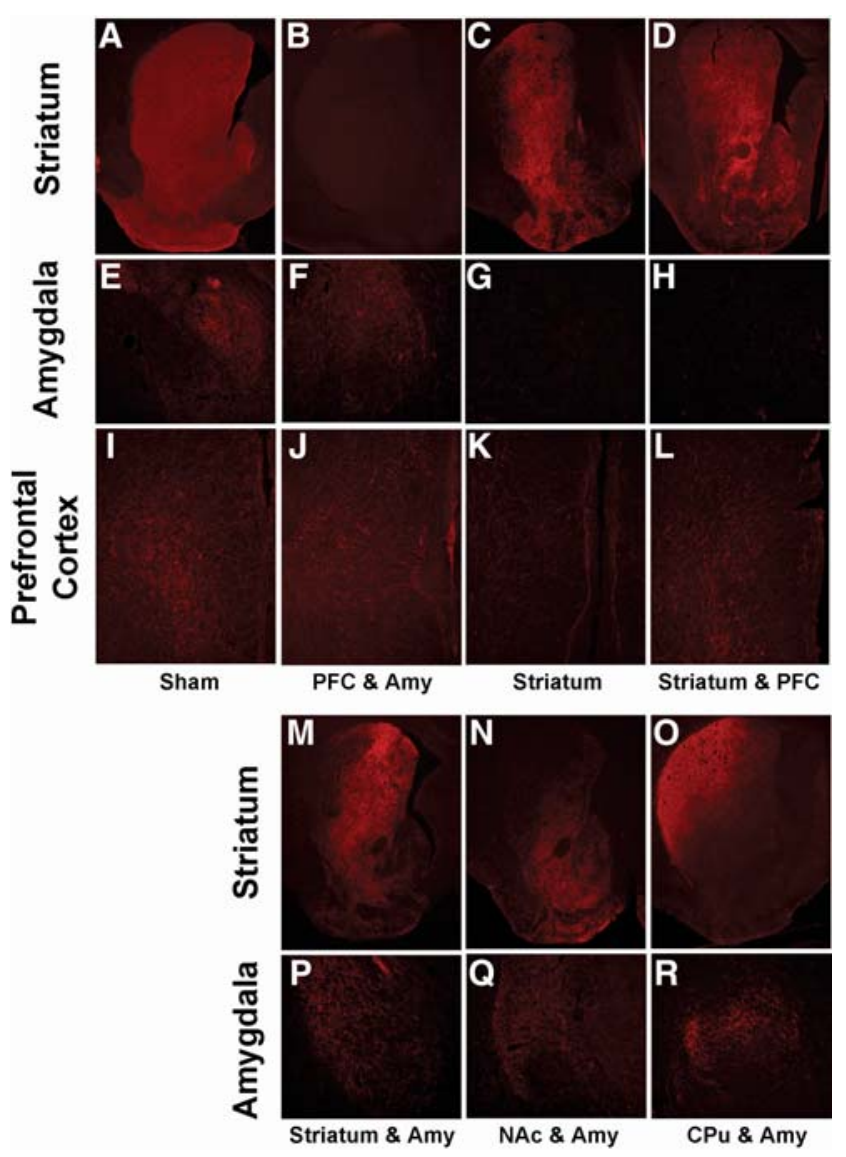

Figure 2. Restoration of $\mathrm{TH}$ expression in PFC, striatum, and amygdala of vrDD mice. TH immunostaining (in red) was visualized in coronal sections of brains from control and vrDD mice. $(A-D)$ TH expression pattern is shown in sections of the striatum of sham mice $(A)$, vrDD mice that had no CAV2-Cre injected into the striatum $(B)$, and vrDD mice that received CAV2-Cre injections into the whole striatum $(C, D)$. $(E-H)$ TH expression in the amygdala of sham mice $(E)$, vrDD mice that had CAV2-Cre injected into the amygdala $(F)$, and vrDD mice that were not injected with CAV2-Cre into the amygdala $(G, H)$. (I-L) TH expression pattern in the PFC of sham mice $(I)$, vrDD mice that had CAV2-Cre injected into the $\operatorname{PFC}(J, K)$, and $\operatorname{vrDD}$ mice that received no CAV2-Cre injections into the PFC $(L)$. (M-O) TH expression pattern in the striatum of $\operatorname{vrDD}$ mice that received CAV2-Cre injections into the whole striatum $(M)$, into the NAC $(N)$, and into the $\mathrm{CPu}(O)$. $(P-R)$ TH expression in the amygdala of vrDD mice that had CAV2-Cre injected into the amygdala together with the whole striatum $(P)$, the NAc $(Q)$, and into the CPu $(R)$. Annotations on the left refer to the brain areas shown in boxes. Annotations at the bottom of the sections refer to the grouping of vrDD mice according to their CAV2-Cre injection protocol. 
A

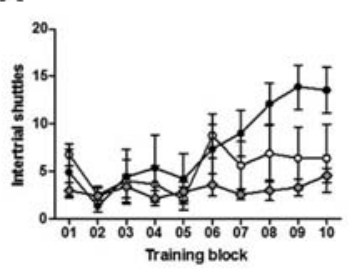

D

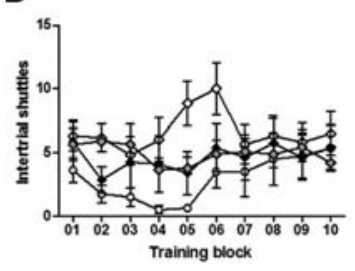

G

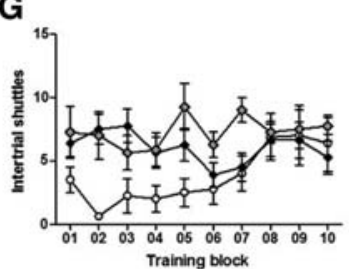

B

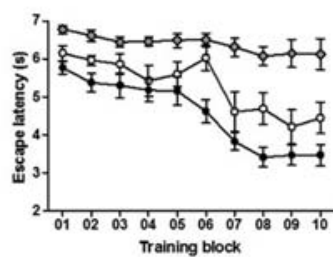

E

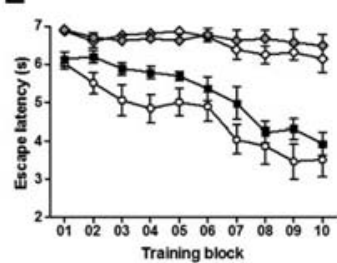

H

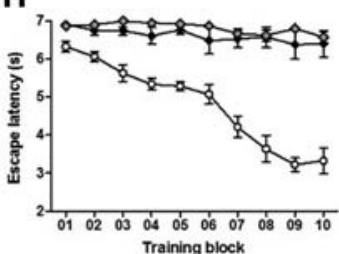

C

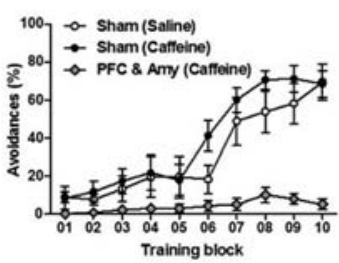

F

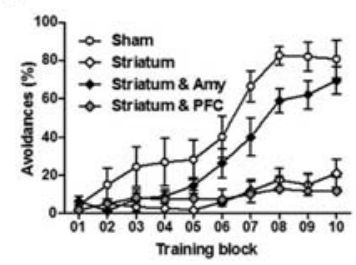

I

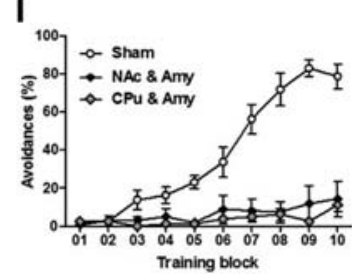

Figure 3. Acquisition of $2 \mathrm{WAA}$ requires DA signaling in both amygdala and the whole striatum. Learning was assessed over a period of $2 \mathrm{~d}$ (100 trials per day); recordings from every 20 trials were combined into a training block and mean scores were calculated per block. $(A-C)$ Intertrial shuttles $(A)$, latencies to escape from the sound cue $(B)$, and percentage of active avoidance responses $(C)$ by salinetreated sham-control $(n=8)$, caffeine-treated sham-control $(n=9)$, and caffeine-treated vrDD mice that had DA signaling restored to the PFC and amygdala $(n=7)$. $(D-F)$ Intertrial shuttles $(D)$, latencies to escape from the sound cue $(E)$, and percentage of active avoidance responses $(F)$ by sham-control $(n=6)$, vrDD mice that had DA signaling restored to the striatum $(n=6)$, to the striatum plus amygdala $(n=8)$, and to the striatum plus the PFC $(n=9)$. $(G-l)$ Intertrial shuttles $(G)$, latencies to escape from the sound cue $(H)$, and percentage of active avoidance responses $(I)$ by sham-control $(n=8)$, vrDD mice that had DA signaling restored to the NAc plus the amygdala $(n=8)$, or to the CPu plus amygdala $(n=8)$. Data are expressed as mean \pm SEM.

of locomotor activity revealed only significant differences between caffeine-treated sham-control and vrDD-PFC and Amy mice throughout trial blocks eight to ten $(P<0.05)$. RM two-way ANOVA of both escape latencies and avoidances revealed significant effects for training (Latencies: $F_{(9,189)}=32.02, P<0.01$; Avoidances: $\left.\quad F_{(9,189)}=41.87, \quad P<0.01\right)$, group (Latencies: $F_{(2,189)}=13.79, P<0.01$; Avoidances: $\left.F_{(2,189)}=10.22, P<0.01\right)$, and training-group interactions (Latencies: $F_{(18,189)}=4.39, P<$ 0.01; Avoidances: $\left.F_{(18,189)}=7.89, P<0.01\right)$. While saline- and caffeine-treated sham-control mice had no differences in avoidances on any given trial block $(P>0.05)$, the escape latencies of caffeine-treated, sham-control mice were significantly lower than of saline-treated, sham-control mice on trial blocks 06 $(P<0.01)$ and $08(P<0.05)$. Caffeine-treated vrDD-PFC and Amy mice had higher escape latencies and reduced avoidances, compared to both caffeine- and saline-treated, sham-control mice, throughout trial blocks $7-10(P<0.01)$. We conclude that treatment with caffeine did not impair 2WAA in sham-control mice and that although caffeine stimulates locomotion in vrDD mice to a degree similar to saline-treated, sham-control mice, manifestation of 2WAA is still absent in vrDD mice that had DA signaling restricted to only the amygdala and PFC.

Next, we analyzed vrDD mice with DA restricted to the striatum alone, to both striatum and amygdala (Striatum and Amy), or to both striatum and PFC (Striatum and PFC).
Locomotor activity by all of these vrDD mice was similar to sham-control mice (Fig. 3D), as shown by RM two-way ANOVA of intertrial shuttles, which showed no significant effects for training $\left(F_{(9,171)}=1.92, P>0.05\right)$, group $\left(F_{(2,179)}=2.78, P>0.05\right)$, or traininggroup interactions $\left(F_{(18,171)}=1.08, P>\right.$ 0.05). Whereas restriction of DA signaling to either striatum or striatum and PFC did not allow for 2WAA, vrDD-Striatum and Amy mice had 2WAA similar to sham-control mice (Fig. 3E,F). RM two-way ANOVA of both escape latencies and avoidances revealed significant effects for training (Latencies: $F_{(9,243)}=20.12, P<0.01$; Avoidances: $\left.F_{(9,243)}=34.01, \quad P<0.01\right), \quad$ group (Latencies: $\quad F_{(3,243)}=30.93, \quad P<0.01$; Avoidances: $\left.F_{(3,243)}=19.34, \quad P<0.01\right)$, and training-group interactions (Latencies: $F_{(27,243)}=3.69, P<0.01$; Avoidances: $\left.F_{(27,243)}=6.30, P<0.01\right)$. Post-hoc comparisons confirmed that escape latencies of vrDD-Striatum and vrDDStriatum and PFC mice were significantly elevated when compared to shamcontrol (trial blocks 3-10, $P<0.01$ ) and vrDD-Striatum and Amy mice (trial blocks 6-10, $P<0.01$ ). Avoidances by vrDD-Striatum and vrDD-Striatum and PFC mice were significantly reduced when compared to sham-control (trial blocks $6-10, P<0.01$ ) and vrDD-Striatum and Amy mice (trial blocks 7-10, $P<0.01)$. Thus, DA signaling in both the striatum and amygdala is sufficient to restore $2 \mathrm{WAA}$.

To test whether DA signaling to striatal subregions, together with the amygdala, might be sufficient for 2WAA, we also tested vrDD mice that had DA signaling restored to the amygdala together with either the NAc or $\mathrm{CPu}$. Although intertrial shuttles were similar to sham-control levels, neither vrDD-NAc and Amy or vrDD-CPu and Amy mice had intact 2WAA (Fig. 3G-I). RM two-way ANOVA of intertrial shuttles showed no significant effects of group $\left(F_{(2,189)}=3.39, P>0.05\right)$ and significant effects of training $\left(F_{(9,189)}=2.44, P<0.05\right)$ and training-group interactions $\left(F_{(18,189)}=2.40, P<0.05\right)$. Post-hoc comparisons confirmed that vrDD-NAc and Amy mice had more shuttles than sham mice during trial block 2 and that vrDD-CPu and Amy had more shuttles than sham mice during trial blocks 2 and 5. RM two-way ANOVA of both escape latencies and avoidances revealed significant effects for training (Latencies: $F_{(9,189)}=36.42, P<0.01$; Avoidances: $\left.F_{(9,189)}=24.88, P<0.01\right)$, group (Latencies: $F_{(2,189)}=49.12, \quad P<0.01$; Avoidances: $\left.F_{(2,189)}=30.29, \quad P<0.01\right)$, and training-group interactions (Latencies: $F_{(18,189)}=18.90, P<0.01$; Avoidances: $F_{(18,189)}=$ 24.88, $P<0.01$ ). Post-hoc comparisons confirmed that escape latencies by vrDD-NAc and Amy and vrDD-CPu and Amy mice were significantly longer than latencies by sham-control mice (trial blocks $3-10, P<0.01$ ). Avoidances by vrDD-NAc and Amy and vrDD-CPu and Amy mice were significantly reduced when compared to sham-control mice (trial blocks 6-10, $P<0.01$ ). We conclude that DA signaling in the entire striatum $(\mathrm{CPu}$ and NAc) plus the amygdala is necessary for mice to learn 2WAA, 
even though restoration to either $\mathrm{CPu}$ or NAc was sufficient to restore locomotion.

\section{Shock escape behavior requires DA signaling in the striatum and amygdala}

In addition to examining the contributions of DA signaling to performance of the conditioned avoidance to the sound cue (2WAA), we also analyzed the requirements of DA signaling to the simpler shock-escape behavior. Whenever a mouse did not show 2 WAA, it received a foot shock, which could either be endured for 2 sec or terminated by moving to the other side of the test box.

Caffeine-treated vrDD-PFC and Amy mice did not escape the shock (Fig. 4A), as verified by RM two-way ANOVA analysis of shock-escape latencies, which revealed significant effects of
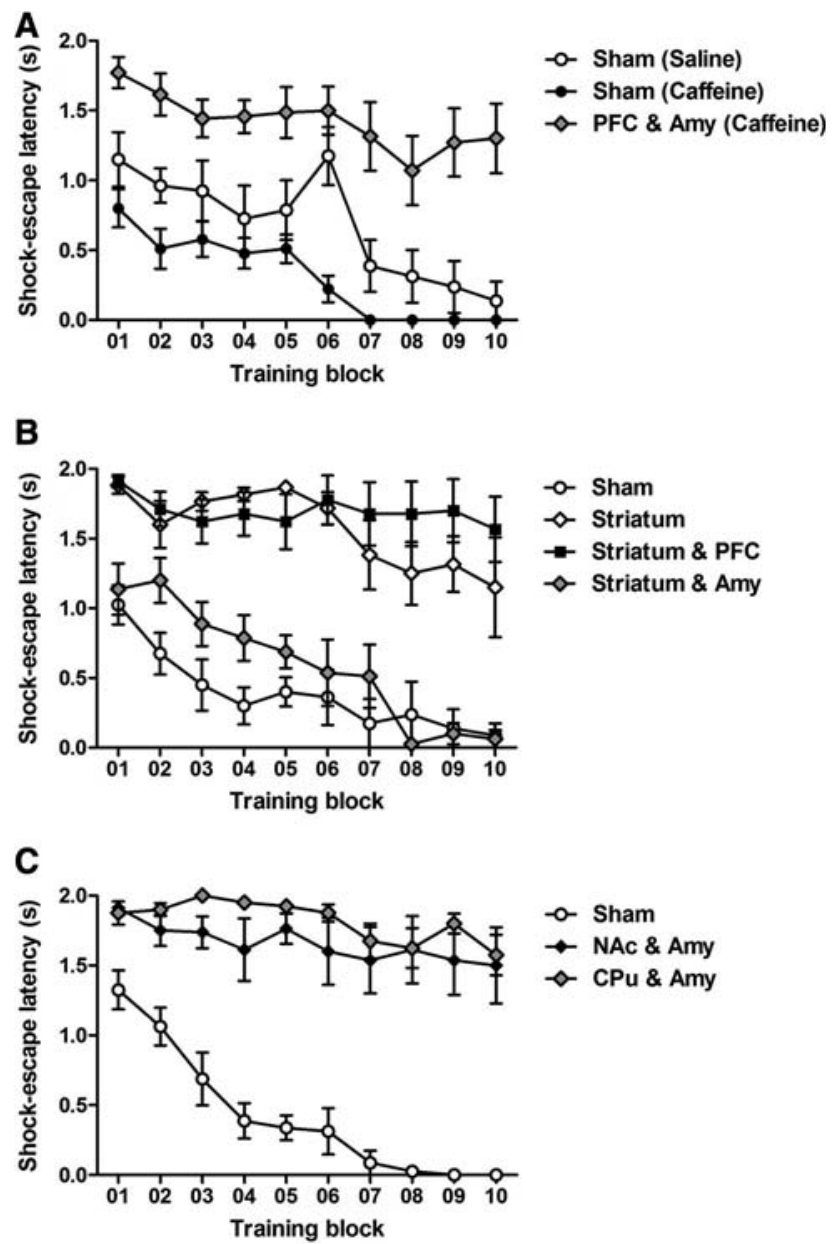

Figure 4. Acquisition of simple shock-escape behavior requires DA signaling in both amygdala and the whole striatum. Learning was assessed over a period of $2 \mathrm{~d}$ (100 trials per day); recordings from every 20 trials were combined into a training block and mean scores were calculated per block. For those trials when the shock was not avoided by escaping to the sound cue in time, latencies to escape from the foot shock were recorded. (A) Shock-escape latencies by saline-treated sham-control $(n=8)$, caffeine-treated sham-control $(n=9)$, and caffeine-treated vrDD mice that had DA signaling restored to the PFC and amygdala $(n=7)$. (B) Shock-escape latencies by sham-control $(n=6)$, vrDD mice that had DA signaling restored to the striatum $(n=6)$, to the striatum plus amygdala $(n=8)$, and to the striatum plus the PFC $(n=9)$. (C) Shock-escape latencies by sham-control $(n=8)$, vrDD mice that had DA signaling restored to the NAc plus the amygdala $(n=8)$, or to the CPu plus amygdala $(n=8)$. Data are expressed as mean \pm SEM. training $\left(F_{(9,189)}=17.76, P<0.01\right)$, group $\left(F_{(2,189)}=22.45, P<\right.$ $0.01)$, and training-group interactions $\left(F_{(18,189)}=1.76, P<\right.$ 0.05). Post-hoc comparisons of shock-escape latencies demonstrated significant differences between saline-treated shamcontrol and vrDD-PFC and Amy mice for trial blocks 4-5 and $7-10(P<0.05)$ and also significant differences between caffeinetreated sham-control and vrDD-PFC and Amy mice for all trial blocks $(P<0.01)$.

Mice with DA signaling restricted to either striatum or striatum and PFC also failed to avoid the shock; however, vrDD-Striatum and Amy mice had shock-escape behavior similar to sham-control mice (Fig. 4B). RM two-way ANOVA of shock-escape latencies revealed significant effects for training $\left(F_{(9,243)}=14.26, P<0.01\right)$, group $\left(F_{(3,243)}=29.28, P<0.01\right)$, and training-group interactions $\left(F_{(27,243)}=2.38, P<0.01\right)$. Post-hoc comparisons confirmed that shock-escape latencies of vrDDStriatum and vrDD-Striatum and PFC mice were significantly longer when compared to sham-control (trial blocks $1-10, P<0.05$ ) and vrDD-Striatum and Amy mice (trial blocks 3-10, $P<0.05$ ).

Restoration of DA signaling to the amygdala together with either NAc or $\mathrm{CPu}$ did not restore shock-escape behavior (Fig. 4C). RM two-way ANOVA of both shock-escape latencies confirmed significant effects for training $\left(F_{(9,189)}=17.78, P<0.01\right)$, group $\left(F_{(2,189)}=47.49, P<0.01\right)$, and training-group interactions $\left(F_{(18,189)}=5.63, P<0.01\right)$. Post-hoc comparisons confirmed that shock-escape latencies by vrDD-NAc and Amy and vrDD-CPu and Amy mice were significantly higher than latencies by shamcontrol mice (trial blocks $2-10, P<0.05$ ).

We conclude that only restoration of DA signaling to both amygdala and the entire striatum enabled DD mice to escape the shock. Importantly, restoration of DA signaling to the striatum alone was insufficient to allow shock escape, hence ruling out locomotor activity differences between these mice and DD mice that had DA signaling restored to the striatum together with the amygdala.

\section{DA action in the striatum is sufficient to maintain well-learned 2WAA}

To determine after how many training days of 2WAA mice would be overtrained, we tested extinction of 2WAA in control mice after 4 or $9 \mathrm{~d}$ of training (Supplemental Fig. S01). RM two-way ANOVA of avoidances per total training/extinction day confirmed significant effects of pretraining $\left(F_{(1,44)}=15.30, P<0.01\right)$, number of extinction sessions $\left(F_{(4,44)}=61.47, P<0.01\right)$, and interaction effects $\left(F_{(4,44)}=2.52, P<0.05\right)$. Hence, training for $9 \mathrm{~d}$ is more resistant to extinction than training for $4 \mathrm{~d}$. Based on this result, we trained, DD, vrDD sham-control mice for $9 \mathrm{~d}$. Sham-control mice were trained for $9 \mathrm{~d}$ with saline and then tested on day 10 with caffeine. Caffeine treatment did not affect 2WAA in overtrained control mice (Fig. 5A), as indicated by RM two-way ANOVA, which failed to detect significant effects of training block $\left(F_{(4,56)}=0.53, P>0.05\right)$, or of treatment $\left(F_{(1,56)}=0.13, P>0.05\right)$ and interaction $\left(F_{(4,56)}=1.80, P>0.05\right)$.

DD mice were trained for $9 \mathrm{~d}$ with L-Dopa injections and then tested on day 10 with caffeine. After this, they were retrained for $2 \mathrm{~d}$ with L-Dopa and then tested with saline. Whereas caffeine enabled DD mice to perform 2WAA for the first trial block, salinetreated DD mice were totally incapable of performing $2 \mathrm{WAA}$ (Fig. 5B), as indicated by RM two-way ANOVA of avoidances, which detected significant effects of training block $\left(F_{(4,128)}=\right.$ 5.82, $P<0.01)$, of treatment $\left(F_{(1,128)}=7.07, P<0.01\right)$, and of interaction $\left(F_{(12,128)}=8.26, P<0.01\right)$. Post-hoc comparisons confirmed that avoidances by saline-treated DD mice were reduced compared to any group of L-Dopa or caffeine-treated DD mice 
A

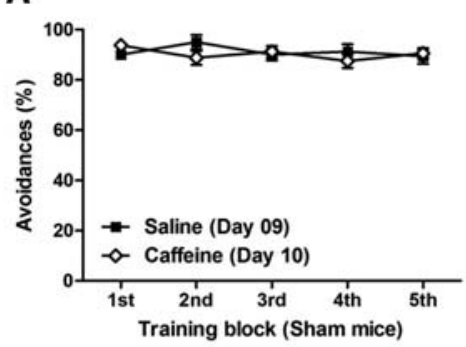

C

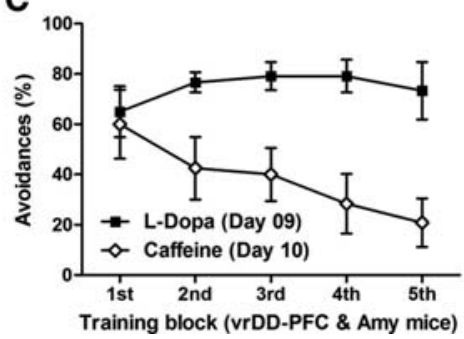

B

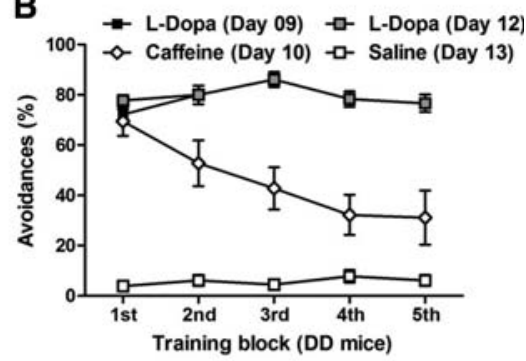

D

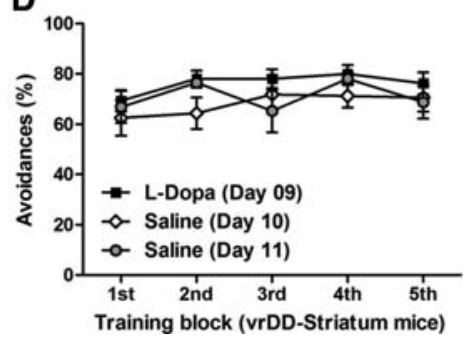

Figure 5. DA signaling in the striatum is sufficient to maintain 2WAA. (A) Sham-control mice $(n=8)$ were trained for $9 \mathrm{~d}$ (five blocks of 20 trials per block per day) with saline injections given before each training session. After this pretraining, they were tested on day 10 after caffeine treatment. The percentage of avoidances per 20-trial block on day 9 (saline treatment) and day 10 (caffeine treatment) are shown. $(B)$ DD mice $(n=9)$ were trained for $9 \mathrm{~d}$ with L-Dopa, then tested on the following day after injection with caffeine, retrained for $2 \mathrm{~d}$ with L-Dopa and then tested on the following day with saline. The percentage of avoidances per 20-trial block on day 9 (L-Dopa treatment) and day 10 (saline treatment) are shown. (C) vrDD mice that had DA synthesis restricted to PFC and amygdala $(n=7)$ were trained with L-Dopa for $9 \mathrm{~d}$ and then tested on the following day after injection with caffeine. The percentage of avoidances per 20-trial block on day 9 (L-Dopa treatment) and day 10 (caffeine treatment) are shown. $(D) \operatorname{vrDD}$ mice that had DA synthesis restricted to entire striatum $(n=8)$ were trained with L-Dopa for $9 \mathrm{~d}$ and then tested on two following days after injection with saline. The percentage of avoidances per 20-trial block on day 9 (L-Dopa treatment), day 10 (saline treatment), and day 11 (saline treatment) are shown. Data are expressed as mean \pm SEM.

$(P<0.01)$. However, avoidances by caffeine-treated DD mice were only significantly reduced on trial blocks $2-5$.

Two groups of vrDD mice that did not learn 2WAA were then trained for $9 \mathrm{~d}$ with L-Dopa and tested without further L-Dopa treatment. One vrDD group had DA synthesis restored only to the amygdala and PFC; it was tested in the presence of caffeine to overcome their locomotor deficit. The other group of vrDD mice had DA synthesis restored to the whole striatum. Caffeine-treated vrDD-PFC and Amy mice were unable to maintain 2WAA similar to levels reached in the presence of L-Dopa (Fig. 5C). Although two-way ANOVA of avoidances did not detect a significant effect of training block $\left(F_{(4,40)}=2.24, P>0.05\right)$, effects of both treatment $\left(F_{(1,40)}=8.88, P<0.05\right)$ and interaction $\left(F_{(4,40)}=5.43, P<0.01\right)$ were statistically significant. In contrast, saline-treated vrDD-Striatum mice maintained avoidances similar to levels reached in the presence of L-Dopa (Fig. 5D). Two-way ANOVA did not detect any significant effects of training block $\left(F_{(4,84)}=2.42, P>0.05\right)$, treatment $\left(F_{(2,84)}=1.11, P>0.05\right)$, or interaction effects $\left(F_{(8,56)}=0.89, P>0.05\right)$ for avoidances of welltrained vrDD mice after treatment with L-Dopa or saline. We conclude that after 2 WAA is successfully acquired, DA signaling is still required for performance and DA signaling in the striatum only is sufficient to maintain 2WAA.

\section{Discussion}

Common approaches to study the involvement of DA signaling in behavior aim at preventing DA signaling by either killing DA neurons or pharmacological blockade of DA receptors (Ungerstedt 1971; Dickinson et al. 2000). Our strategy to investigate the function of DA signaling for 2WAA is essentially different. First, with the lack of DA being the status quo for DD mice, we can study behavior in the absence of DA and compare it to performance after pharmacological reconstitution of DA synthesis with L-Dopa (Palmiter 2008). Second, using viral gene therapy we can permanently restore DA signaling in distinct brain areas of DD mice, which allows us to examine where DA is sufficient for specific aspects of behavior (Hnasko et al. 2006; Darvas and Palmiter 2009, 2010).

Although DD mice can learn some simple behaviors in a DA-depleted state (Denenberg et al. 2004; Hnasko et al. 2005; Robinson et al. 2005), vrDD mice cannot learn that a tone predicts the shock and avoid it by moving to the opposite chamber or to even escape after the shock commences without DA signaling in both the striatum and amygdala. Because locomotor activity by vrDD mice that had intact $2 \mathrm{WAA}$ was the same as that of vrDD mice that received viral injections into the whole striatum or into striatal subregions, the deficits in 2WAA are not due to locomotor impairments. Similarly, locomotor activity of DD mice or caffeine-stimulated vrDD mice that had DA restored to the PFC and amygdala was also comparable to vrDD mice that had intact 2WAA. Thus, the inability to perform 2WAA was not due to a locomotor deficit. In addition, we have previously shown that DD mice have intact acoustic startle, prepulse inhibition, and shock reactivity (Fadok et al. 2009), which argues against impaired sensory abilities (including the ability to respond to shocks) as an alternative explanation for deficits in 2WAA by some groups of vrDD mice.

Surprisingly, the performance of the vrDD-PFC-Amy mice that had been trained with L-Dopa and tested with caffeine declined gradually on the test day. Their performance was very good during the first training block but then gradually decayed during subsequent training blocks, rather than dropping precipitously, as observed with DD mice trained with L-Dopa and then given saline. This result suggests that, although there is some memory of the training the performance decays during the course of the test session in the absence of DA. Because performance after caffeine injection of vrDD-PFC-Amy and DD mice were essentially the same, this initial performance does not require DA signaling in PFC or amygdala. This decay of performance in the absence of striatal dopamine suggests that, although a behavior is well learned, a striatal dopamine is always necessary to sustain that behavior by providing a reinforcement signal (Schultz 2007). In the case of conditioned avoidance, dopamine could be necessary for either the reinforcement properties of the shock itself or of the shock avoidance response (Mowrer 1947).

Our results expand upon earlier studies that demonstrated slower avoidance learning after pharmacological striatal DA depletion in rats (Halladay et al. 2000). Our finding, that 2WAA is absent in vrDD mice when DA signaling is restored to the striatum alone, but intact when restored to both amygdala and striatum, is strong evidence for an interaction of DA signaling in these two brain regions. Pavlovian conditioning experiments 
have demonstrated that DA signaling in the amygdala is crucial for the establishment of associations between the conditioned stimulus and an aversive unconditioned event (Lamont and Kokkinidis 1998; Greba et al. 2001; Pezze and Feldon 2004; de Oliveira et al. 2009; Fadok et al. 2009). DD mice are unable to learn a fear-potentiated startle response, but it can be restored with either L-Dopa or viral restoration of DA signaling in the VTA (Fadok et al. 2009) or NAc and amygdala (Fadok et al. 2010). We therefore suggest that the contingency between the sound cues used during 2WAA training and the foot shocks cannot be learned without DA signaling in the amygdala and NAc (a major projection area of the VTA); hence, the DD mice cannot learn the conditioned avoidance response either. Interestingly, the restoration of DA signaling to either amygdala and NAc or amygdala and $\mathrm{CPu}$ is insufficient to support 2WAA. These results likely reflect different functional contributions of DA signaling to the NAc and the $\mathrm{CPu}$. One hypothesis proposes that the NAc is important for Pavlovian-types of associations linking cues to particular outcomes, whereas the $\mathrm{CPu}$ is divided into a medial system that supports action-goal associations and a lateral system participates in stimulus-response associations (Ikemoto 2007). Both of these systems contribute to behavioral selection and are thought to be important for instrumental learning. We suggest that striatal DA signaling is crucially involved in allowing mice to adopt and exhibit the conditioned avoidance response by facilitating (1) Pavlovian learning mechanisms to associate the sound cue with the foot shock, (2) generation of a goal-directed avoidance response, and then (3) a reflex-like execution of the avoidance response. However, once an avoidance response is acquired, DA signaling in the striatum is sufficient to maintain performance in vrDD mice, suggesting that DA signaling in the amygdala is only required for the acquisition of this behavior. This inference is consistent with studies that demonstrated a modulation of striatal memory processes by the amygdala (Packard 2009). In particular, whereas post-training intra-amygdala infusion of the indirect catecholamine agonist D-amphetamine enhanced memory in a striatum-dependent, water-maze task, neural inactivation of the amygdala immediately prior to a retention test did not block this memory-enhancing effect (Packard et al. 1994; Packard and Teather 1998).

A surprising corollary of our results is that DA signaling to the PFC appears to be unnecessary to acquire 2WAA because mice with DA signaling in striatum plus amygdala can learn 2WAA, whereas mice with DA signaling in striatum and PFC cannot. DA projections from the VTA and excitatory projections from the amygdala converge in the medial PFC, forming a functional circuit that has been implicated in cued fear conditioning (Maren and Quirk 2004; Gabbott et al. 2005; Floresco and Tse 2007). D1R-like and D2R-like receptors are expressed by both interneurons and pyramidal cells in the PFC (Goldman-Rakic et al. 2000; Negyessy and Goldman-Rakic 2005), where they exert complex excitatory and inhibitory actions (Seamans et al. 2001; Tseng and O'Donnell 2004). Thus, it is possible that although DA signaling in the PFC can enhance the excitatory neurotransmission from the amygdala (Floresco and Tse 2007), a total depletion of DA in the PFC, like that found in our vrDD mice, might have unpredicted consequences. Another possibility is that cuedfear conditioning involves a few pairings between the cue and usually a much stronger fearful event, whereas mice require $>100$ parings to master 2WAA; therefore the role of the PFC might be masked in 2WAA procedures. Lending support to our result is the observation that rats with lesioned DA projections to the PFC have no deficits on a conditioned-avoidance task (Koob et al. 1984).

Taken together, our observations demonstrate that an interaction between DA signaling in both amygdala and the whole striatum is necessary for the acquisition of 2WAA. Yet, after prolonged training (perhaps after a habit is formed) this interaction is no longer necessary and 2WAA can be performed with DA signaling restricted to the striatum.

\section{Methods}

\section{Drugs}

L-Dopa (Sigma) was dissolved in saline solution containing $0.25 \%$ ascorbic acid and then filtered. Caffeine (Sigma) was dissolved in saline solution. All drugs were administered intraperitoneally.

\section{Animals}

All experiments were approved by the Institutional Animal Care and Use Committee at the University of Washington. The DD mice were generated and maintained with daily administration of L-Dopa as described (Hnasko et al. 2006). Mice of both sexes were maintained on a mixed C57Bl/6 X 129/SvEv genetic background. They were housed under a 12 -h, light-dark cycle in a temperature-controlled environment with food and water available ad libitum except during testing. The CAV2-Cre virus was generated and titered as described (Kremer et al. 2000). The virus preparation had a titer of $6 \times 10^{12}$ particles $/ \mathrm{mL}$. Bilateral injections of $0.5 \mu \mathrm{L}$ of CAV2-Cre into the amygdala ( $y=-1.5 \mathrm{~mm}$ posterior to Bregma, $x= \pm 2.75 \mathrm{~mm}$ lateral to midline, $z=4.75 \mathrm{~mm}$ ventral from the skull surface), $\mathrm{CPu}(y=0.9, x= \pm 1.75, z=3.0)$, NAc $(y=0.9, x= \pm 1.0, z=4.8)$, and PFC $(y=1.94, x= \pm 0.3$, $z=2.75$ ) were performed on anesthetized (isoflurane) $2-3$ mo old male and female DD or wild-type mice (referred to as sham controls). Virally injected DD (vrDD) mice were removed from the L-Dopa treatment 2 wk after the viral injection and were allowed one more week of recovery before behavioral testing began. DD mice (whether treated with caffeine or L-Dopa) received daily L-Dopa injections at least $6 \mathrm{~h}$ after completion of the experimental sessions. We injected $7 \mathrm{DD}$ and 17 sham mice with CAV2-Cre into the PFC together with the amygdala.

\section{Immunohistochemistry}

After transcardial perfusion (4\% paraformaldehyde) of deeply anesthetized mice, brains were removed, cryoprotected in 30\% sucrose, frozen in isopentane, and sectioned on a cryostat. Proteins were detected on free-floating $30-\mu \mathrm{m}$ brain sections by using a rabbit anti-TH (1:2000; Chemicon) antibody in conjunction with a CY3-labeled IgG secondary antibody (1:200; Jackson ImmunoResearch).

\section{Behavioral studies}

2WAA was assessed in an apparatus that consisted of four identical PACS-30 two-way shuttle boxes (Columbus Instruments). Each box was divided into two identical compartments by an opaque wall that had an opening allowing the mice to traverse from one compartment to the other. The grid floor was made of stainless steel rods that were connected to a constant current shock generator that delivered a foot shock to the entire grid. Inside the compartments were photobeams that detected the presence or absence of the mouse in each compartment. The boxes were illuminated during the experimental trials by two diffuse light sources that were mounted on the ceilings of each compartment. Each chamber was equipped with a sound-cue generator that was situated above the opening between the two compartments. Mice received 100 trials per day, each of which was followed by an intertrial interval (ITI). Each trial started with the onset of a 5 -sec sound cue $(2.5 \mathrm{kHz}, 80 \mathrm{~dB})$. If the mouse moved to the other chamber within this time the sound cue was terminated. 
Avoidance failure was followed by the delivery of a $0.3-\mathrm{mA}$ foot shock to the floor of the shuttle box (co-presented with the sound cue) that could last for a maximum of $2 \mathrm{sec}$ and was terminated if the mouse moved to the other chamber. In either case or even if the mouse did not move at all, the protocol resumed with a 40-sec ITI, during which mice were allowed to shuttle freely between chambers. During each trial, the latency to escape from the sound cue, escape from the foot shock, and the number of avoidances during presentation of the sound cue were recorded. During each ITI only the number of shuttles between chambers was recorded. Results from each of the 20 trials or ITIs were combined into training a block.

Acquisition of 2WAA was recorded over a period of two sessions separated by $24 \mathrm{~h}$. To allow DD mice that were virally rescued in the PFC and amygdala to perform 2WAA, $15 \mathrm{mg} / \mathrm{kg}$ caffeine was given $10 \mathrm{~min}$ prior to both training sessions. Caffeine acts as an antagonist of adenosine receptors, which are present on medium spiny neurons in the striatum. This treatment stimulates locomotion in DD mice, allowing them to perform simple behavioral tasks (Denenberg et al. 2004; Robinson et al. 2005). In addition, one group of sham animals received the same caffeine treatment and another group of sham mice received saline injections $10 \mathrm{~min}$ prior to both training sessions.

Extinction training of 2WAA was assessed to determine the number of training days needed for overtraining of 2WAA. Control mice were trained for either 4 or $9 \mathrm{~d}$ as described above and then subjected to extinction sessions. During these sessions all conditions were equal to acquisition training conditions, with the exception that now there were no more foot shocks following the sound cues.

Maintenance of 2WAA after overtraining was assessed by enabling vrDD mice that did not show 2WAA during acquisition to perform 2WAA through systemic restoration of DA synthesis by treatment with L-Dopa $(30 \mathrm{mg} / \mathrm{kg})$. We chose vrDD mice with DA synthesis restored to the PFC together with the amygdala and $\operatorname{vrDD}$ mice with DA synthesis restored to the striatum. These vrDD mice were from a new, experimentally naïve group of mice. This training with L-Dopa treatment continued for $9 \mathrm{~d}$ (overtraining). Then, for a test training session on day 10, the L-Dopa treatment was substituted with either caffeine $(15 \mathrm{mg} /$ $\mathrm{kg}$ ), for vrDD mice that have no DA in the striatum or with saline. Sham-control and vrDD mice that had received viral injections into the PFC together with the amygdala were tested for one day after administration of caffeine. Because overtrained vrDD mice that were injected into the whole striatum showed intact 2WAA when given saline, we tested them for one more day in the presence of saline. In addition, we also overtrained naïve DD mice in the presence of L-Dopa and then tested them after caffeine injection. They were then retrained with L-Dopa and tested after saline injection. This procedure was employed to demonstrate the necessity of DA signaling for performing 2WAA.

\section{Acknowledgments}

This investigation was supported in part by the Pacific Northwest Udall Center NS062684 (M.D.) and by PHS NRSA 2T32 GM007270 from NIGMS (J.P.F.). We thank Dr. Miguel Chillon (Vector Production Unit of CBATEG at Universitat Autonoma Barcelona) for preparing the CAV2-Cre virus, Glenda Froelick for brain sectioning, and Valerie Wall for maintaining the mouse colony.

\section{References}

Bjorklund A, Dunnett SB. 2007. Dopamine neuron systems in the brain: An update. Trends Neurosci 30: 194-202.
Brischoux F, Chakraborty S, Brierley DI, Ungless MA. 2009. Phasic excitation of dopamine neurons in ventral VTA by noxious stimuli. Proc Natl Acad Sci 106: 4894-4899.

Da Cunha C, Angelucci ME, Canteras NS, Wonnacott S, Takahashi RN. 2002. The lesion of the rat substantia nigra pars compacta dopaminergic neurons as a model for Parkinson's disease memory disabilities. Cell Mol Neurobiol 22: 227-237.

Dalley JW, Cardinal RN, Robbins TW. 2004. Prefrontal executive and cognitive functions in rodents: Neural and neurochemical substrates. Neurosci Biobehav Rev 28: 771-784.

Darvas M, Palmiter RD. 2009. Restriction of dopamine signaling to the dorsolateral striatum is sufficient for many cognitive behaviors. Proc Natl Acad Sci 106: 14664-14669.

Darvas M, Palmiter RD. 2010. Restricting dopaminergic signaling to either dorsolateral or medial striatum facilitates cognition. J Neurosci 30: 1158-1165.

Davidson AB, Weidley E. 1976. Differential effects of neuroleptic and other psychotropic agents on acquisition of avoidance in rats. Life Sci 18: 1279-1284.

Dayan P, Balleine BW. 2002. Reward, motivation, and reinforcement learning. Neuron 36: 285-298.

Denenberg VH, Kim DS, Palmiter RD. 2004. The role of dopamine in learning, memory, and performance of a water escape task. Behav Brain Res 148: $73-78$.

de Oliveira AR, Reimer AE, Brandao ML. 2009. Role of dopamine receptors in the ventral tegmental area in conditioned fear. Behav Brain Res 199: $271-277$.

Dickinson A, Smith J, Mirenowicz J. 2000. Dissociation of Pavlovian and instrumental incentive learning under dopamine antagonists. Behav Neurosci 114: 468-483.

Ehrlich I, Humeau Y, Grenier F, Ciocchi S, Herry C, Luthi A. 2009. Amygdala inhibitory circuits and the control of fear memory. Neuron 62: $757-771$.

Fadok JP, Dickerson TM, Palmiter RD. 2009. Dopamine is necessary for cue-dependent fear conditioning. J Neurosci 29: 11089-11097.

Fadok JP, Darvas M, Dickerson TM, Palmiter RD. 2010. Long-term memory for Pavlovian fear conditioning requires dopamine in the nucleus accumbens and basolateral amygdala. PLOS ONE 5: doi:10.1371/ journal.pone.0012751.

Fibiger HC, Phillips AG, Zis AP. 1974. Deficits in instrumental responding after 6-hydroxydopamine lesions of the nigro-neostriatal dopaminergic projection. Pharmacol Biochem Behav 2: 87-96.

Floresco SB, Tse MT. 2007. Dopaminergic regulation of inhibitory and excitatory transmission in the basolateral amygdala-prefrontal cortical pathway. J Neurosci 27: 2045-2057.

Gabbott PL, Warner TA, Jays PR, Salway P, Busby SJ. 2005. Prefrontal cortex in the rat: Projections to subcortical autonomic, motor, and limbic centers. J Comp Neurol 492: 145-177.

Goldman-Rakic PS, Muly 3rd. EC3rd, Williams GV. 2000. D(1) receptors in prefrontal cells and circuits. Brain Res Brain Res Rev 31: 295-301.

Greba Q, Gifkins A, Kokkinidis L. 2001. Inhibition of amygdaloid dopamine D2 receptors impairs emotional learning measured with fear-potentiated startle. Brain Res 899: 218-226.

Halladay AK, Coyne T, Sharifi J, Seto J, Wagner GC. 2000. Avoidance responding following amphetamine-induced dopamine depletion. Pharmacol Toxicol 87: 211-217.

Hnasko TS, Sotak BN, Palmiter RD. 2005. Morphine reward in dopamine-deficient mice. Nature 438: 854-857.

Hnasko TS, Perez FA, Scouras AD, Stoll EA, Gale SD, Luquet S, Phillips PE, Kremer EJ, Palmiter RD. 2006. Cre recombinase-mediated restoration of nigrostriatal dopamine in dopamine-deficient mice reverses hypophagia and bradykinesia. Proc Natl Acad Sci 103: 8858-8863.

Ikemoto S. 2007. Dopamine reward circuitry: Two projection systems from the ventral midbrain to the nucleus accumbens-olfactory tubercle complex. Brain Res Rev 56: 27-78.

Joshua M, Adler A, Mitelman R, Vaadia E, Bergman H. 2008. Midbrain dopaminergic neurons and striatal cholinergic interneurons encode the difference between reward and aversive events at different epochs of probabilistic classical conditioning trials. J Neurosci 28: 11673-11684.

Kalivas PW, Duffy P. 1995. Selective activation of dopamine transmission in the shell of the nucleus accumbens by stress. Brain Res 675: 325-328.

Koob GF, Simon H, Herman JP, Le Moal M. 1984. Neuroleptic-like disruption of the conditioned avoidance response requires destruction of both the mesolimbic and nigrostriatal dopamine systems. Brain Res 303: $319-329$.

Kremer EJ, Boutin S, Chillon M, Danos O. 2000. Canine adenovirus vectors: An alternative for adenovirus-mediated gene transfer. J Virol 74: 505-512.

Lamont EW, Kokkinidis L. 1998. Infusion of the dopamine D1 receptor antagonist SCH 23390 into the amygdala blocks fear expression in a potentiated startle paradigm. Brain Res 795: 128-136. 
Maren S, Quirk GJ. 2004. Neuronal signalling of fear memory. Nat Rev Neurosci 5: 844-852.

McGaugh JL. 2004. The amygdala modulates the consolidation of memories of emotionally arousing experiences. Annu Rev Neurosci 27: $1-28$.

Mowrer OH. 1947. On the dual nature of learning-a reinterpretation of conditioning and problem solving. Harv Educ Rev 17: $102-148$.

Negyessy L, Goldman-Rakic PS. 2005. Subcellular localization of the dopamine D2 receptor and coexistence with the calcium-binding protein neuronal calcium sensor-1 in the primate prefrontal cortex. $J$ Comp Neurol 488: 464-475.

Packard MG. 2009. Anxiety, cognition, and habit: A multiple memory systems perspective. Brain Res 1293: 121-128.

Packard MG, Teather LA. 1998. Amygdala modulation of multiple memory systems: Hippocampus and caudate-putamen. Neurobiol Learn Mem 69: $163-203$.

Packard MG, Cahill L, McGaugh JL. 1994. Amygdala modulation of hippocampal-dependent and caudate nucleus-dependent memory processes. Proc Natl Acad Sci 91: 8477-8481.

Palmiter RD. 2008. Dopamine signaling in the dorsal striatum is essential for motivated behaviors: Lessons from dopamine-deficient mice. Ann N $Y$ Acad Sci 1129: 35-46.

Pezze MA, Feldon J. 2004. Mesolimbic dopaminergic pathways in fear conditioning. Prog Neurobiol 74: 301-320.

Posluns D. 1962. An analysis of chlorpromazine-induced suppression of the avoidance response. Psychopharmacologia 3: 361-373.

Robinson S, Sandstrom SM, Denenberg VH, Palmiter RD. 2005. Distinguishing whether dopamine regulates liking, wanting, and/or learning about rewards. Behav Neurosci 119: 5-15.
Schultz W. 2002. Getting formal with dopamine and reward. Neuron 36: 241-263.

Schultz W. 2007. Behavioral dopamine signals. Trends Neurosci 30: 203-210.

Seamans JK, Gorelova N, Durstewitz D, Yang CR. 2001. Bidirectional dopamine modulation of GABAergic inhibition in prefrontal cortical pyramidal neurons. J Neurosci 21: $3628-3638$.

Seymour B, Dolan R. 2008. Emotion, decision making, and the amygdala. Neuron 58: 662-671.

Shionoya K, Datiche F. 2009. Inactivation of the basolateral amygdala impairs the retrieval of recent and remote taste-potentiated odor aversion memory. Neurobiol Learn Mem 92: 590-596.

Smith AJ, Li M, Becker S, Kapur S. 2007. Linking animal models of psychosis to computational models of dopamine function.

Neuropsychopharmacology 32: 54-66.

Tseng KY, O’Donnell P. 2004. Dopamine-glutamate interactions controlling prefrontal cortical pyramidal cell excitability involve multiple signaling mechanisms. J Neurosci 24: 5131-5139.

Ungerstedt U. 1971. Adipsia and aphagia after 6-hydroxydopamine induced degeneration of the nigro-striatal dopamine system. Acta Physiol Scand Suppl 367: 95-122.

van der Heyden JA, Bradford LD. 1988. A rapidly acquired one-way conditioned avoidance procedure in rats as a primary screening test for antipsychotics: Influence of shock intensity on avoidance performance. Behav Brain Res 31: 61-67.

Wise RA. 2004. Dopamine, learning and motivation. Nat Rev Neurosci 5: 483-494.

Received October 12, 2010; accepted in revised form December 7, 2010. 

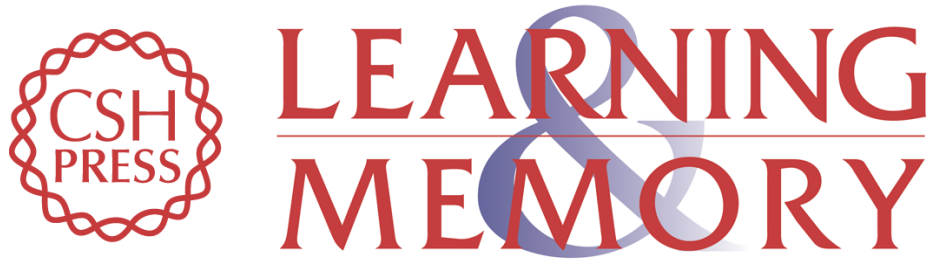

\section{Requirement of dopamine signaling in the amygdala and striatum for learning and maintenance of a conditioned avoidance response}

Martin Darvas, Jonathan P. Fadok and Richard D. Palmiter

Learn. Mem. 2011, 18:

Access the most recent version at doi:10.1101//m.2041211

Supplemental
Material http://learnmem.cshlp.org/content/suppl/2011/02/15/18.3.136.DC1

References This article cites 48 articles, 11 of which can be accessed free at: http://learnmem.cshlp.org/content/18/3/136.full.html\#ref-list-1

License

Email Alerting Receive free email alerts when new articles cite this article - sign up in the box at the Service top right corner of the article or click here. 